Check for updates

Cite this: RSC Adv., 2017, 7, 25469

Received 10th April 2017

Accepted 2nd May 2017

DOI: $10.1039 / \mathrm{c} 7 \mathrm{ra04051b}$

rsc.li/rsc-advances

\title{
High-yield synthesis and fine-tuning aspect ratio of (200) faceted gold nanorods by the $\mathrm{pH}$-adjusting method $\uparrow$
}

\author{
Yumin Leng, (D) *ad Xunjun Yin, ${ }^{d}$ Fang Hu, ${ }^{b}$ Yuehong Zou, ${ }^{d}$ Xiaojing Xing, ${ }^{c}$ Bo Li, ${ }^{c}$ \\ Yongming Guo, (D) ${ }^{c}$ Liqun Ye (D) *c and Zhiwen Lu*a
}

\begin{abstract}
Tight-controlling of the aspect ratios (ARs) and fine-tailoring of the crystallographic facets of gold nanorods (GNRs) are critical for their further applications in material, biological, and medical fields. However, the highyield synthesis of GNRs with certain facets and ARs is still challenging because it requires grasping of various components and complicated interactions in the reaction system. Herein, we first report the $\mathrm{pH}$-adjusting method to synthesize uniform and monodispersed GNRs in high yield with the (200) facet and fine-tuned their ARs within an optimal pH range. Through optimizing the experimental parameters, we found that the formation of GNRs was significantly influenced by the concentrations of silver ions and cetyltrimethylammonium bromide (CTAB). Based on the precise control over the quantity of silver ions and $C T A B$ additives, we further optimized the $\mathrm{pH}$ in the buffer system. Under the optimized weakly acidic conditions ( $\mathrm{pH}$ 5.5-7.0), $\mathrm{HAuCl}_{4}$ was reduced by $\mathrm{NH}_{2} \mathrm{OH}$ to form single-crystalline GNRs with a preferential growth along the [200] facet (i.e. [100] direction), which was supported by transmission electron microscopy (TEM) and X-ray diffraction (XRD). Interestingly, there was a linear relationship between the ARs and $\mathrm{pH}$ values over a narrow $\mathrm{pH}$ range of 5.5-6.5. The $\mathrm{pH}$-dependent reducing ability of $\mathrm{NH}_{2} \mathrm{OH}$ enhanced with the increasing $\mathrm{pH}$.
\end{abstract}

\section{Introduction}

Since its discovery in the $1990 \mathrm{~s},{ }^{1}$ gold nanorods (GNRs) have attracted significant interest due to their charming properties in optics and catalysis obtained on varying their length and width..$^{2-9}$ GNRs exhibit intense longitudinal surface plasmon resonance (LSPR), whose wavelength is controlled by the ratio of the length to the width of the GNRs (the aspect ratio, AR), as well as a weaker transverse surface plasmon resonance (TSPR) that is located at $\sim 520 \mathrm{~nm}^{2-9}$ The LSPR is tuned towards longer wavelengths and into the near-infrared spectrum as the AR increases. To date, a number of successful methods, such as electrochemical, ${ }^{1}$ photochemical, ${ }^{10,11}$ seed-mediated, ${ }^{12}$ and template methods ${ }^{13}$ have been developed to synthesize GNRs. The seed-mediated growth method has become the most popular approach to realize precise control over both the

${ }^{a}$ College of Physics and Electronic Engineering, Nanyang Normal University, Nanyang 473061, China.E-mail:ymleng@nynu.edu.cn; lzw@nynu.edu.cn

${ }^{b}$ Faculty of Materials Science \& Chemical Engineering, Ningbo University, Ningbo 315201, China

${ }^{c}$ College of Chemistry and Pharmaceutical Engineering, Nanyang Normal University, Nanyang 473061, China.E-mail: yeliquny@163.com

${ }^{d}$ Ningbo Institute of Materials Technology \& Engineering (NIMTE), Chinese Academy of Sciences, Ningbo 315201, China

$\dagger$ Electronic supplementary information (ESI) available: Supplementary Figures. See DOI: $10.1039 / \mathrm{c} 7 \mathrm{ra} 04051 \mathrm{~b}$ longitudinal and transverse dimensions of the GNRs. ${ }^{14}$ The tight-controlling of the GNR AR achieves the tunability of the plasmon-dominated light absorption and scattering properties. Light absorbed by GNRs is converted into heat, which is useful for photothermal cancer therapy ${ }^{15-20}$ and the scattered light is useful for bioimaging..$^{19-21}$

The capability of fine-tailoring its crystallographic facets, which play pivotal roles in determining the affinity, specificity, and dynamics of the interactions between the ligand molecules and the GNR surfaces, is of the same importance as the control over GNR ARs. ${ }^{9,22,23}$ Moreover, precise facet control is vital to the optimization of the catalytic performance of GNRs. Quantitative assignment of the crystallographic facets exposed on the surfaces of GNRs, however, has long been a subject under intense debate., ${ }^{93-29}$ It remains a significant challenge to quantitatively correlate the catalytic activities with the surface structures due to the poor control over the GNR facets.

Conventional single-crystalline GNRs are typically prepared by seed-mediated growth in the presence of $\mathrm{Ag}^{+}, \mathrm{OH}^{-}$, and cetyltrimethylammonium bromide (CTAB). ${ }^{14,21,23,30}$ The first step of this method is to synthesize gold seeds (ca. 2-4 nm in diameter). The GNR growth is initiated by adding gold seeds into a growth solution containing $\mathrm{Au}^{0}, \mathrm{Ag}^{+}, \mathrm{CTAB}$, and reducing agents. The GNR size, AR, and yield are sensitive to (i) the size and nature of the seeds (affected by the aging time and the standing time during and after the synthesis), ${ }^{31}$ (ii) the quantity 
of the $\mathrm{Ag}^{+}$and CTAB additives, ${ }^{32}$ and (iii) the $\mathrm{pH}$ value of the growth solution. ${ }^{3-36}$ For example, Chou's group recently reported the size-controlled synthesis of gold nanoparticles via controlling the $\mathrm{pH}$ value. ${ }^{36}$ Patra and Kurdi recently researched the role of $\mathrm{OH}^{-}$in the formation of gold nanowires at extreme pH values. ${ }^{30}$ The size and shape of the gold nanoparticles are significantly affected by $\mathrm{pH}^{\mathbf{3 0 , 3 6}}$ Thus, high-yield synthesis of GNRs with certain facets and ARs is still a challenge because it requires grasping of various components and their interactions in the reaction system.

Herein, we report that the (200) facet can be controllably created on the surfaces of single-crystalline GNRs and their ARs can be precisely controlled by adjusting the $\mathrm{pH}$ of the growth solution. In our experiment, a simple synthesis process was developed for high-yield GNRs by adjusting the $\mathrm{pH}$ of the buffer system in the presence of silver ions and high concentrations of CTAB. Precise control over the $\mathrm{pH}$ and the quantity of $\mathrm{Ag}^{+}$and $\mathrm{CTAB}$ are critical to the yield of GNRs. $\mathrm{HAuCl}_{4}$ is reduced by $\mathrm{NH}_{2} \mathrm{OH}$ in the controllable solution to form single-crystalline GNRs with a preferential growth along the [200] facet (i.e. [100] direction), which is supported by transmission electron microscopy (TEM) and X-ray diffraction (XRD).

\section{Experimental}

\section{Materials and instrumentation}

Chloroauric acid tetrahydrate $\left(\mathrm{HAuCl}_{4} \cdot 4 \mathrm{H}_{2} \mathrm{O}\right)$, silver nitrate $\left(\mathrm{AgNO}_{3}\right)$, sodium borohydride $\left(\mathrm{NaBH}_{4}\right)$, hydroxylamine hydrochloride $\left(\mathrm{NH}_{2} \mathrm{OH} \cdot \mathrm{HCl}\right)$, and $\mathrm{CTAB}$ were purchased from Shanghai Chemical Reagent Co. Ltd (China). All the chemicals were analytical grade reagents and used as received. Milli-Q water (18 $\mathrm{M} \Omega$ ) was used throughout the experiments. All the glass containers were washed with aqua regia $\left(\mathrm{HCl} / \mathrm{HNO}_{3}=\right.$ $3: 1(\mathrm{v} / \mathrm{v})$, strongly corrosive) and then cleaned with Milli-Q water.

The UV-vis absorption spectra were obtained using a Lambda 950 UV-vis spectrophotometer purchased from Perkin Elmer. TEM was performed using a Tecnai F20 instrument and operated at $200 \mathrm{kV}$. X-ray powder diffraction (XRD) was performed using a Bruker D8 Advance/Discover diffractometer (Bruker Co. Ltd., Germany) with $\mathrm{Cu} \mathrm{K} \alpha$ radiation $(\lambda=1.5406 \AA)$. Scanning electron microscopy (SEM) was carried out using an S4800 instrument.

\section{Preparation of the gold seed solution}

The CTAB-capped gold seeds were prepared according to a literature procedure. ${ }^{12}$ CTAB solution $(5.0 \mathrm{~mL}, 0.20 \mathrm{M})$ was mixed with $5.0 \mathrm{~mL}$ of $5.0 \times 10^{-4} \mathrm{M} \mathrm{HAuCl}_{4}$. Freshly prepared ice-cold $0.01 \mathrm{M} \mathrm{NaBH}_{4}$ solution $(0.60 \mathrm{~mL})$ was quickly added to the gold salt and CTAB mixture under vigorous stirring, leading to the formation of a brownish yellow solution. The seed solution was freshly used.

\section{The pH-controlled growth solution}

The route for the synthesis of GNRs was a modified literature procedure. ${ }^{12,37}$ The growth solutions were prepared as follows:
$0.10 \mathrm{~mL}$ of $0.01 \mathrm{M} \mathrm{AgNO}_{3}$ was added to a CTAB solution ( $5 \mathrm{~mL}$, $0.20 \mathrm{M}$ ) at $25{ }^{\circ} \mathrm{C}$ and then $1.0 \mathrm{~mL}$ of $5 \mathrm{mM} \mathrm{HAuCl}_{4}$ was added and stirred. Subsequent reduction of $\mathrm{HAuCl}_{4}$ using $\mathrm{NH}_{2}$ $\mathrm{OH} \cdot \mathrm{HCl}(1 \mathrm{~mL}, 0.10 \mathrm{M})$ led to the color change of the solution from dark yellow to colorless. The $\mathrm{pH}$ value of the growth solution was adjusted using $0.2 \mathrm{M} \mathrm{NaOH}$ solution and measured using a pH meter.

\section{GNR overgrowth}

Herein, $15 \mu \mathrm{L}$ of the as-prepared gold seed solution was added into the $\mathrm{pH}$ controllable growth solutions, which were kept in a water bath $\left(28^{\circ} \mathrm{C}\right)$ for $24 \mathrm{~h}$. The obtained GNRs solutions were centrifuged at $8000 \mathrm{rpm}$ for $8 \mathrm{~min}$ and resuspended in deionized water. After the removal of the excess CTAB, the final suspensions of GNRs were analyzed via TEM, SEM, and XRD.

\section{Results and discussion}

\section{Optimization of the experimental parameters}

We synthesized GNRs following a previously reported seedmediated growth method using a CTAB surfactant system ${ }^{12,37}$ with some minor modifications. To achieve a high yield of the GNRs, we investigated the effect of (i) the quantity of the $\mathrm{Ag}^{+}$ and $\mathrm{CTAB}$ additives and (ii) the $\mathrm{pH}$ of the growth solution on the GNR synthesis. First of all, the $\mathrm{pH}$ value of the growth solution was fixed at 6.0, and 0.2 M of CTAB was selected, and different concentrations of $\mathrm{Ag}^{+}$were examined. After this, $0 \mathrm{~mL}, 0.05 \mathrm{~mL}$, $0.10 \mathrm{~mL}$, and $0.15 \mathrm{~mL}$ of $\mathrm{AgNO}_{3}(0.01 \mathrm{M})$ was added, and the final concentrations of $\mathrm{AgNO}_{3}$ in the growth solutions were about $0 \mathrm{M}, 6.6 \times 10^{-5} \mathrm{M}, 1.3 \times 10^{-4} \mathrm{M}$, and $2 \times 10^{-4} \mathrm{M}$, respectively. When $\mathrm{AgNO}_{3}$ was not added, GNRs, nanospheres, and triangle nanoparticles were produced, as shown in Fig. S1a (ESI $\dagger)$. The appropriate addition of $\mathrm{Ag}^{+}$ions $\left(1.3 \times 10^{-4} \mathrm{M}\right)$ was essential for the preparation of GNRs in very high yield, as shown in Fig. S1c (ESI $\dagger$ ). Therefore, $1.3 \times 10^{-4} \mathrm{M} \mathrm{Ag}^{+}$was chosen as the optimum additive in the experiments. The effect of $\mathrm{Ag}^{+}$during the formation of the GNRs was previously investigated and it depended on the reducing and capping agents. ${ }^{35}$ Herein, $\mathrm{Ag}^{+}$could assist the elongation of the CTAB template and restrict the growth of the GNRs. Second, the effect of CTAB on the synthesis of the GNRs was investigated while keeping the $\mathrm{pH}$ of the growth solution at 6.0 and the $\mathrm{Ag}^{+}$concentration at 1.3 $\times 10^{-4}$ M. Fig. S2 (ESI $\dagger$ ) shows the TEM images of the gold nanoparticles obtained at different concentrations of CTAB. It was obvious that the yield of GNRs significantly increased as the concentration of CTAB increased from $0.1 \mathrm{M}$ to $0.2 \mathrm{M}$. The high yield of the GNRs could also be obtained at a concentration of CTAB above $0.2 \mathrm{M}$. Upon decreasing the temperature, the higher concentration of CTAB would be easier to crystallize and affect the GNRs synthesis. Thus, $0.2 \mathrm{M}$ of CTAB was chosen as the optimal reaction condition in the experiments. Finally, the $\mathrm{pH}$ effect on the GNRs synthesis was investigated while keeping the $\mathrm{Ag}^{+}$and CTAB concentrations at $1.3 \times 10^{-4} \mathrm{M}$ and $0.2 \mathrm{M}$, respectively. Fig. 1 shows the TEM images of the gold nanoparticles obtained under the different $\mathrm{pH}$ conditions. Under

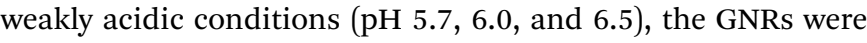




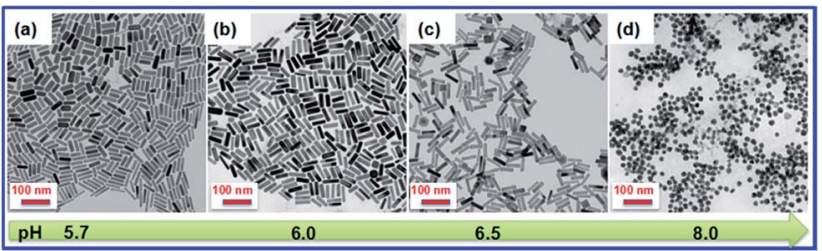

Fig. 1 TEM images of the gold nanoparticles in different $\mathrm{pH}$ solutions: (a) $\mathrm{pH}$ 5.7, (b) $\mathrm{pH}$ 6.0, (c) $\mathrm{pH}$ 6.5, and (d) $\mathrm{pH}$ 8.0. 0.2 $\mathrm{M}$ of CTAB and 1.3

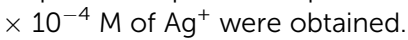

synthesized as shown in Fig. 1a-c. Under weakly alkaline conditions ( $\mathrm{pH} 8.0$ ), spherical gold nanoparticles with uniform diameters of $c a .22 \mathrm{~nm}$ were obtained as the main products (Fig. 1d). Thus, the weakly acidic conditions were applied in our experiments.

\section{Fine-tuning the AR of GNRs}

The usual way to tune the ARs of GNR is to regulate the $\mathrm{Ag}^{+}$ concentrations; ${ }^{8}$ herein, we tried to achieve precise control over the ARs of the GNRs by adjusting the $\mathrm{pH}$ of the growth solution from 5.5 to 7.0 in a buffer system. Fig. 2 shows the typical TEM images and UV-vis absorption spectra of the GNRs obtained under the different $\mathrm{pH}$ conditions. We found that the ARs of the GNRs increased as the $\mathrm{pH}$ value of the growth solution increased under the weakly acidic conditions. Interestingly, a linear relationship $\left(R^{2}=0.994\right)$ was observed between the ARs and $\mathrm{pH}$ values in a narrow range of 5.5-6.5 (see the inset of Fig. 2). As is well-known, the absorption spectra of the GNRs are characterized by two bands: the transverse plasmon band $\left(\lambda_{\mathrm{T}}\right)$ located at $\sim 520 \mathrm{~nm}$ and longitudinal plasmon band $\left(\lambda_{\mathrm{L}}\right)$

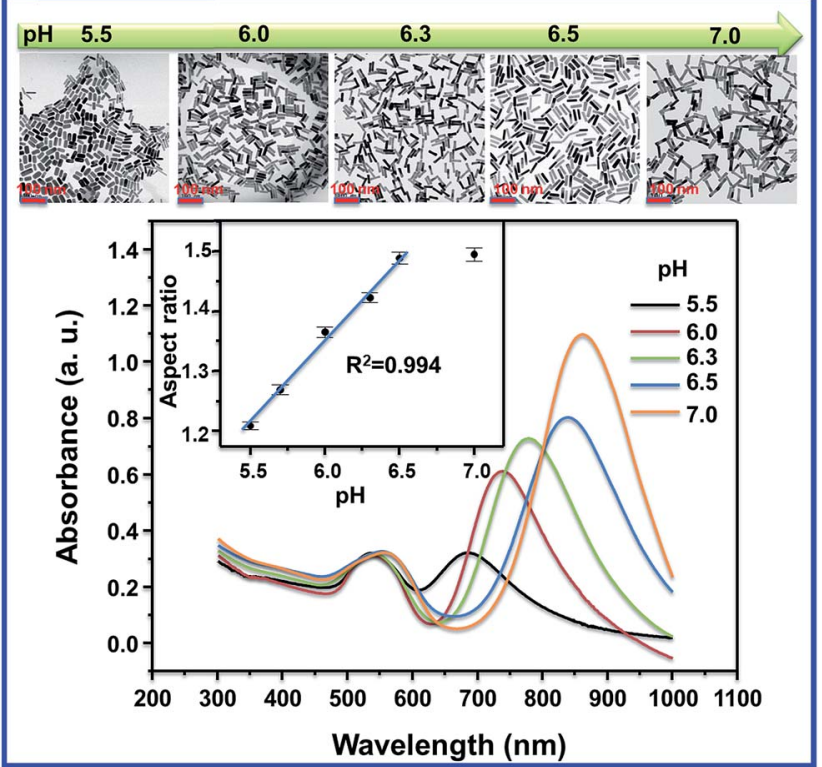

Fig. 2 TEM images and the UV-vis absorption spectra of the GNRs synthesized by adjusting the $\mathrm{pH}$ of the growth solution from 5.5 to 7.0 . Inset: the AR of the GNRs as a function of the pH. 0.2 M of CTAB and $1.3 \times 10^{-4} \mathrm{M}$ of $\mathrm{Ag}^{+}$were selected. appearing at a longer wavelength in the visible-NIR range. ${ }^{38-40}$ As $\lambda_{\mathrm{L}}$ is mainly dependent on the AR of the GNRs, there is a red shift in the absorbance peak at $\lambda_{\mathrm{L}}$ with an increase in the AR of the GNRs. As shown in Fig. 2, the $\lambda_{\mathrm{L}}$ is red-shifted from $685 \mathrm{~nm}$ to $860 \mathrm{~nm}$, due to the increased AR of the GNRs induced by an increase in the $\mathrm{pH}$ value from 5.5 to 7.0. These experimental results indicate that the $\mathrm{pH}$ of the growth solution is vital for precise control over the AR of the GNRs since $\mathrm{pH}$ has a strong influence on the reducing power of $\mathrm{NH}_{2} \mathrm{OH}$. The $\mathrm{pH}$-dependent reducing ability of $\mathrm{NH}_{2} \mathrm{OH}$ is enhanced upon increasing the pH. ${ }^{41,42}$ Moreover, the $\mathrm{OH}^{-}$ions can play a significant role during the synthesis of GNRs. ${ }^{30}$

\section{Precise control over the crystallographic facets of GNRs}

For GNRs with face-centered cubic (fcc) structures, the lowindex (111) facet is thermodynamically more stable than the (200) facet and is thus highly favored during the nanocrystal growth. ${ }^{38}$ The XRD spectra show that the synthesized GNRs are usually with the dominant $\{111\}$ family of planes. ${ }^{38}$ Herein, we found that the GNRs with the dominant $\{200\}$ family of planes could be synthesized if the $\mathrm{pH}$ of the growth solution was adjusted within an optimal range.

We investigated the crystal structure of the as-synthesized GNRs under weakly acidic conditions. The crystal structure of the GNRs was first investigated using high-resolution transmission electron microscopy (HRTEM) and electron diffraction of a random individual GNR. As shown in Fig. 3a, the interdistance of the lattice planes was approximately $0.205 \mathrm{~nm}$, which could be indexed to the (200) surface. ${ }^{43}$ Moreover, the electron diffraction pattern (Fig. 3b) has a highly symmetrical dotted lattice, which reveals the single-crystalline nature of the
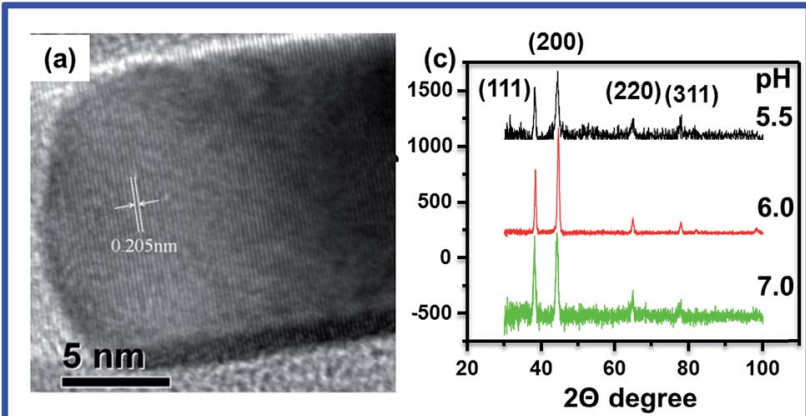

(b)

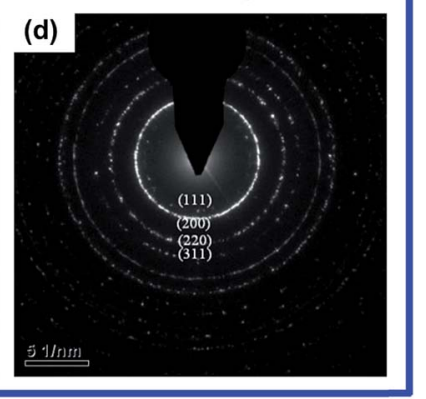

Fig. 3 (a) HRTEM image and (b) electron diffraction pattern of an individual GNR. (c) XRD and (d) SAED patterns of the as-prepared GNRs under weakly acidic conditions ( $\mathrm{pH}$ in the range of 5.5-7.0). 
GNRs. The pattern could be indexed to the [011] zone axis of the GNRs, further confirming that the GNRs were crystalline and grew along the [200] axis. To assess the overall quality and purity of the facetted nanoparticles, the XRD spectra and selected area electron diffraction (SAED) patterns for the as-synthesized GNRs were obtained and are presented in Fig. $3 \mathrm{c}$ and $\mathrm{d}$. Herein, four main characteristic peaks for gold at $38.34^{\circ}, 44.35^{\circ}$, $64.72^{\circ}$, and $77.61^{\circ}$ corresponding to the Miller indices ( 1111$),(2$ 00 , , ( $\left.\begin{array}{lll}2 & 2 & 0\end{array}\right)$, and ( $\left.\begin{array}{lll}3 & 1 & 1\end{array}\right)$ were observed and confirmed the facecentered cubic (fcc) crystalline geometry of the GNRs (JCPDS file no. 4-0783). A relatively high (200) diffraction intensity was detected under the weakly acidic conditions ( $\mathrm{pH}$ in the range of 5.5-7.0). This explicitly demonstrated that the as-synthesized GNRs were primarily dominated by the $\{200\}$ family of planes. Under a low $\mathrm{pH}$ environment ( $\mathrm{pH}$ 5.5-7.0), $\mathrm{Au}(\mathrm{I})$ was slowly reduced to $\mathrm{Au}(0)$ and this condition was helpful for the selective absorption of $\mathrm{Au}(0)$ by the $\{200\}$ planes of the GNRs under the regulation of $\mathrm{CTAB}$, which capped $\mathrm{Au}(0)$ and bound more easier to the $\left\{\begin{array}{lll}2 & 0 & 0\end{array}\right\}$ facet than the $\{111\}$ facet. ${ }^{44}$ The SAED pattern with a relatively brighter circular ring corresponding to the (200) surfaces further showed that the GNRs obtained were highly single crystalline with the dominant $\{200\}$ family of planes. The high yield of the GNRs can be obtained under weakly acidic conditions, as shown in Fig. 4.

\section{The growth process of GNRs: insight into the growth mechanism}

We synthesized GNRs at $\mathrm{pH} 6.5$ and obtained their UV-vis absorption spectra along with the growth time. As shown in Fig. 5, there are considerable red shifts in the $\lambda_{\mathrm{L}}$ band and minimal red shifts in the $\lambda_{\mathrm{T}}$ band with time, which means that the mean length and width of the GNRs increase with the growth time. ${ }^{45} \lambda_{\mathrm{L}}$ was very sensitive to the growth time, whereas $\lambda_{\mathrm{T}}$ was comparatively less sensitive to growth time.

The proposed growth mechanism of GNRs is shown in the inset of Fig. 5. The dynamic formation of a bilayer of CTAB on the gold surfaces via the hydrocarbon tails may indeed provide enough stabilization during the GNRs growth, in a zipper fashion, for the formation of longer nanorods for longer

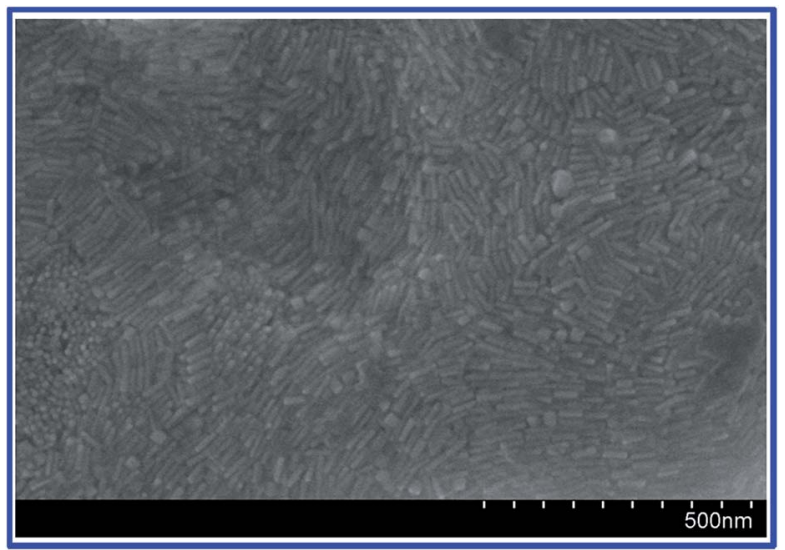

Fig. 4 SEM image of the GNRs obtained under weakly acidic conditions.

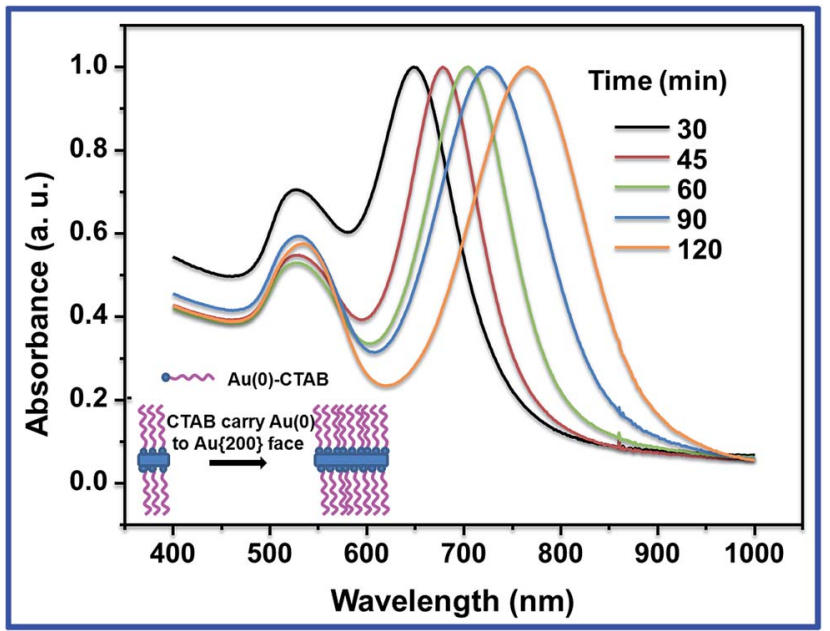

Fig. 5 The normalized UV-vis optical spectral evolution of the GNRs under weakly acidic conditions. The $\lambda_{L}$ bands gradually red-shifted with the growth time. Inset: the proposed mechanism for the CTABdirected GNR growth.

surfactant tails. ${ }^{46}$ During the formation process of the GNRs, it was observed that a decrease or increase in the amount of $\mathrm{Ag}^{+}$ $\left(1.3 \times 10^{-4} \mathrm{M}\right)$ added could lead to the formation of non-rodshaped (quasi spherical or irregularly grown spiked) particles. $\mathrm{Ag}^{+}$could assist the CTAB template elongation with its ability to induce monolayer formation. ${ }^{12} \mathrm{Ag}^{+}$ions could also be adsorbed on the gold nanoparticle surface in the form of $\mathrm{AgBr}$ and restrict the growth of the GNRs. Herein, fine-tuning the $\mathrm{pH}$ value of the growth solution was critical for precise control over the AR and facet of the GNRs since the $\mathrm{pH}$ has a strong influence on the reducing power of $\mathrm{NH}_{2} \mathrm{OH}$. Due to the $\mathrm{pH}$-dependent reducing ability, $\mathrm{NH}_{2} \mathrm{OH}$ is a much weaker reductant under weakly acidic conditions than under weakly alkaline conditions. In our experiment, the difference in the reaction rate under different $\mathrm{pH}$ conditions can be judged from the change in the colour of the solution: at $\mathrm{pH}$ 8.0, the growth solution immediately turned to wine red when the seed was added; at $\mathrm{pH} 6.5$, a delay in the color change of about 1 hour was observed; at pH 5.5, a color change from colorless to light brown was observed after 10 hours. At low $\mathrm{pH}$ ( $\mathrm{pH}$ 5.5-7.0), $\mathrm{Au}(\mathrm{III})$ was slowly reduced by $\mathrm{NH}_{2} \mathrm{OH}$ to $\mathrm{Au}(0)$; this condition was helpful for the selective absorption of $\mathrm{Au}(0)$ by the $\{200\}$ planes of the GNRs under the regulation of $\mathrm{CTAB}$, which capped $\mathrm{Au}(0)$ through the formation of $\mathrm{Au}-\mathrm{Br}$ bonds and bound more easier to the $\{200\}$ than the $\{111\}$ facets. ${ }^{44}$ However, under alkaline conditions (e.g. $\mathrm{pH}>$ 8.0), with the increased reducing power of $\mathrm{NH}_{2} \mathrm{OH}, \mathrm{Au}(\mathrm{III})$ was quickly reduced to $\mathrm{Au}(0)$, which quickly grew around the gold seeds as the core to form the gold spheres. Thus, the $\mathrm{pH}$ value of the growth solution plays an important role in the process of the as-synthesized GNRs with special ARs and facets.

\section{Conclusions}

In summary, we proposed a simple synthesis process for highyield GNRs by adjusting the $\mathrm{pH}$ of the buffer system in the presence of $\mathrm{Ag}^{+}$ions and high concentrations of CTAB. We 
found that it is critical for GNRs synthesis to precisely control the quantity of the $\mathrm{Ag}^{+}$ions and CTAB additives. Based on an appropriate quantity of the $\mathrm{Ag}^{+}$ions and CTAB additives, we further optimized the $\mathrm{pH}$ of the growth solution. Through finetuning the $\mathrm{pH}$ of the buffer system, we achieved the precise control over the ARs of GNRs, which were highly single crystalline with the dominant $\{200\}$ family of planes. The synthesized GNRs with (200) facets were obtained in high yield and were uniform and monodispersed. Tight-controlling of the ARs and the (200) facets of GNRs show great promise for their further application (e.g. in material, biological, and medical fields) in the future. Significantly, we found that the reducing ability of $\mathrm{NH}_{2} \mathrm{OH}$ can be enhanced upon increasing the $\mathrm{pH}$.

\section{Acknowledgements}

This work was supported by the Natural Science Foundation of China (21607083 and 21602122), Natural Science Foundation of Henan (162300410206), Innovation Scientists and Technicians Troop Construction Projects of Henan Province (No. C20150029), Scientific and Technological Project of Henan Province (162102310484), Natural Science Foundation of Ningbo (2016A610262), and China Postdoctoral Science Foundation (2015M581970).

\section{Notes and references}

1 Y. Y. Yu, S. S. Chang, C. L. Lee and C. R. C. Wang, J. Phys. Chem. B, 1997, 101, 6661-6664.

2 X. Huang, S. Neretina and M. A. El-Sayed, Adv. Mater., 2009, 21, 4880-4910.

3 P. Zijlstra, J. W. M. Chon and M. Gu, Nature, 2009, 459, 410413.

4 L. Vigderman, B. P. Khanal and E. R. Zubarev, Adv. Mater., 2012, 24, 4811-4841.

5 X. N. Hu, Y. Y. Zhao, Z. J. Hu, A. Saran, S. Hou, T. Wen, W. Q. Liu, Y. L. Ji, X. Y. Jiang and X. C. Wu, Nano Res., 2013, 6, 822-835.

6 R. N. Moussawi and D. Patra, J. Phys. Chem. C, 2015, 119, 19458-19468.

7 C. T. Nguyen and R. M. Kasi, Chem. Commun., 2015, 51, 12174-12177.

8 L. Zhang, K. Xia, Z. Lu, G. Li, J. Chen, Y. Deng, S. Li, F. Zhou and N. He, Chem. Mater., 2014, 26, 1794-1798.

9 Q. Zhang, L. Han, H. Jing, D. A. Blom, Y. Lin, H. L. Xin and H. Wang, ACS Nano, 2016, 10, 2960-2974.

10 F. Kim, J. H. Song and P. D. Yang, J. Am. Chem. Soc., 2002, 124, 14316-14317.

11 M. Ahmed and R. Narain, Langmuir, 2010, 26, 18392-18399.

12 B. Nikoobakht and M. A. El-Sayed, Chem. Mater., 2003, 15, 1957-1962.

13 C. B. Gao, Q. Zhang, Z. D. Lu and Y. D. Yin, J. Am. Chem. Soc., 2011, 133, 19706-19709.

14 H. J. Chen, L. Shao, Q. Li and J. F. Wang, Chem. Soc. Rev., 2013, 42, 2679-2724.

15 X. H. Huang, I. H. El-Sayed, W. Qian and M. A. El-Sayed, J. Am. Chem. Soc., 2006, 128, 2115-2120.
16 X. H. Huang, S. Neretina and M. A. El-Sayed, Adv. Mater., 2009, 21, 4880-4910.

17 Z. Shi, W. Ren, A. Gong, X. Zhao, Y. Zou, E. M. B. Brown, X. Chen and A. Wu, Biomaterials, 2014, 35, 7058-7067.

18 L. Cheng, C. Wang, L. Feng, K. Yang and Z. Liu, Chem. Rev., 2014, 114, 10869-10939.

19 T. L. Doane and C. Burda, Chem. Soc. Rev., 2012, 41, 28852911.

20 N. S. Abadeer and C. J. Murphy, J. Phys. Chem. C, 2016, 120, 4691-4716.

21 L. Tong, Q. S. Wei, A. Wei and J. X. Cheng, Photochem. Photobiol., 2009, 85, 21-32.

22 Q. Zhang, Y. Zhou, E. Villarreal, Y. Lin, S. Zou and H. Wang, Nano Lett., 2015, 15, 4161-4169.

23 C. J. Murphy, L. B. Thompson, A. M. Alkilany, P. N. Sisco, S. P. Boulos, S. T. Sivapalan, J. A. Yang, D. J. Chernak and J. Y. Huang, J. Phys. Chem. Lett., 2010, 1, 2867-2875.

24 H. Katz-Boon, C. J. Rossouw, M. Weyland, A. M. Funston, P. Mulvaney and J. Etheridge, Nano Lett., 2011, 11, 273278.

25 E. Carbo-Argibay, B. Rodriguez-Gonzalez, S. Gomez-Grana, A. Guerrero-Martinez, I. Pastoriza-Santos, J. Perez-Juste and L. M. Liz-Marzan, Angew. Chem., Int. Ed., 2010, 49, 93979400.

26 P. L. Gai and M. A. Harmer, Nano Lett., 2002, 2, 771-774.

27 B. Goris, S. Bals, W. V. D. Broek, E. Carbo-Argibay, S. GomezGrana, L. M. Liz-Marzan and G. V. Tendeloo, Nat. Mater., 2012, 11, 930-935.

28 Z. L. Wang, R. P. Gao, B. Nikoobakht and M. A. El-Sayed, J. Phys. Chem. B, 2000, 104, 5417-5420.

29 H. Katz-Boon, M. Walsh, C. Dwyer, P. Mulvaney, A. M. Funston and J. Etheridge, Nano Lett., 2015, 15, 16351641.

30 R. E. Kurdi and D. Patra, Phys. Chem. Chem. Phys., 2017, 19, 5077-5099.

31 J. Watt, B. G. Hance, R. S. Anderson and D. L. Huber, Chem. Mater., 2015, 27, 6442-6449.

32 Q. Zhang, H. Jing, G. G. Li, Y. Lin, D. A. Blom and H. Wang, Chem. Mater., 2016, 28, 2728-2741.

33 K. Okitsu, K. Sharyo and R. Nishimura, Langmuir, 2009, 25, 7786-7790.

34 Z. Sun, W. Ni, Z. Yang, X. Kou, L. Li and J. Wang, small, 2008, 4, 1287-1292.

35 R. N. Moussawi and D. Patra, J. Phys. Chem. C, 2015, 119, 19458-19468.

36 B. Yang, J. Chou, X. Dong, C. Qu, Q. Yu, K. J. Lee and N. Harvey, J. Phys. Chem. C, 2017, 121, 8961-8967.

37 J. Gao, C. M. Bender and C. J. Murphy, Langmuir, 2003, 19, 9065-9070.

38 X. Xu, Y. Zhao, X. Xue, S. Huo, F. Chen, G. Zou and X. Liang, J. Mater. Chem. A, 2014, 2, 3528-3535.

39 D. Xu, J. Mao, Y. He and E. S. Yeung, J. Mater. Chem. C, 2014, 2, 4989-4996.

40 L. A. Austin, B. Kang and M. A. El-Sayed, Nano Today, 2015, 10, $542-558$.

41 M. R. Rahman, F. S. Saleh, T. Okajima and T. Ohsaka, Langmuir, 2011, 27, 5126-5135. 
42 X. Zou, E. Ying and S. Dong, J. Colloid Interface Sci., 2007, 306, 307-315.

43 H. Yoshida, Y. Kuwauchi, J. R. Jinschek, K. J. Sun, S. Tanaka, M. Kohyama, S. Shimada, M. Haruta and S. Takeda, Science, 2012, 335, 317-319.
44 C. J. Johnson, E. Dujardin, S. A. Davis, C. J. Murphy and S. Mann, J. Mater. Chem., 2002, 12, 1765-1770.

45 K. C. Ng and W. Cheng, Nanotechnology, 2012, 23, 105602. 46 J. Gao, C. M. Bender and C. J. Murphy, Langmuir, 2003, 19, 9065-9070. 